\title{
Response of the south Manchester accident rescue team to the earthquake in Armenia and the Lockerbie air disaster
}

\author{
Anthony D Redmond
}

The south Manchester accident rescue team was established over two years ago to deliver senior doctors to acutely ill and seriously injured patients outside hospital. It has three main functions: firstly, medical care at the site of accidents, usually road traffic accidents; secondly, provision of a site medical officer at a major accident; and, thirdly, transfer between hospitals of critically ill patients. It draws on consultants working in intensive care, accident and emergency, burns, and plastic surgery.

On 7 December 1988 an earthquake occurred in Armenia. The disaster unit of the Overseas Development Administration made contact, and members of the rescue team were assembled with experts in crush injury. We were told that a large amount of supplies and equipment had already been sent and that protective clothing would not be required. We ignored this and equipped ourselves with arctic gear and medical supplies. This subsequently proved to be correct, but our supplies and equipment were removed from the aeroplane in London without our knowledge or consent to accommodate other rescue equipment, and we never saw them again.

We received the go ahead from Moscow on 11 December and arrived the next day. Our anxieties increased when it was pointed out that the risks were appreciably greater than had been made public: there was asbestos in the buildings; further earthquakes were likely and a second, stronger one was predicted; a nuclear reactor in the earthquake zone had possibly been affected; and a chemical plant was damaged. Over 100 Russian rescue workers had been killed in a series of aeroplane crashes around Leninakan, and it was put

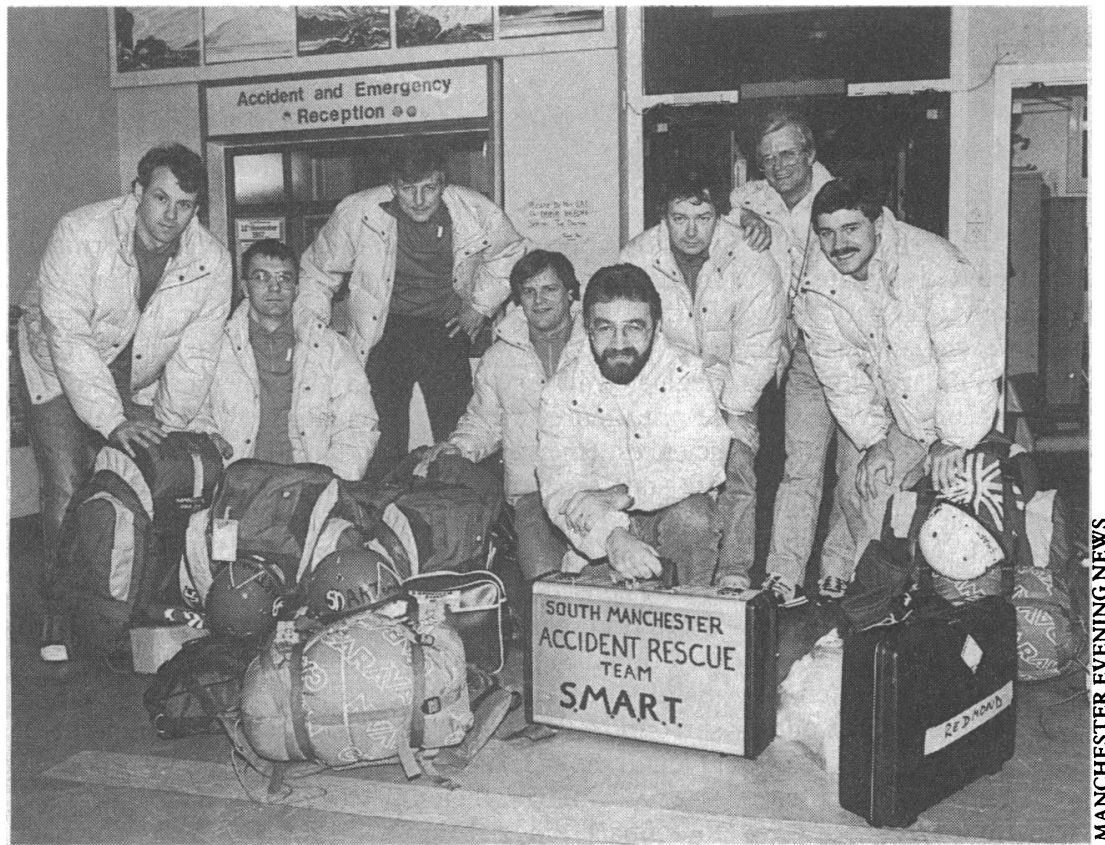

to us that we might return home, but we decided to proceed to Yerevan, the capital. We arrived in fairly good weather that quickly deteriorated. We unloaded the aeroplane by hand and then travelled the $130 \mathrm{~km}$ or so up the mountain in an old bus, arriving in Leninakan at dusk. The journey was tense and tiring. Virtually all the traffic was coming the other way as the city was being evacuated, and only lorries loaded with empty coffins were getting past the blockade of tanks. Hundreds of people flooded the roads; they carried bundles of clothing and flocked around our bus like a continuous wave of sheep.

The city was completely devastated. An ITN cameraman found a student from Yerevan, who had returned to Leninakan to find the body of his fiancée, and in the dark the three of us located what we were told was the KGB office, where we learnt that there was no food, water, electricity, or shelter. The atmosphere in the city was very threatening. A riot had already occurred around a food wagon near where my colleagues were waiting, and shots were fired. We had travelled from Moscow with a Canadian dog team and a group of firemen from Kent, and all agreed that our present position was unsafe. Eventually we found the United States camp at a small military air base. The national team put up tents for us in the dark at $-20^{\circ} \mathrm{C}$ and gave us food and water. We had been without sleep for over 36 hours.

\section{Kidnapped rescue workers}

News arrived that a child had been heard beneath the rubble and a team was required urgently. The Canadian dog team with two members of our rescue team left with local Armenians in an unmarked car. They had not been gone long when we were told of patients with gunshot wounds. It was also rumoured that the Armenians were refusing to evacuate Leninakan and were threatening to take rescue workers hostage with false stories of trapped victims, usually children. In the small hours two officers of the Austrian army arrived, and I decided to travel back with them to the city to locate the casualty clearing station. Bodies and severed limbs lay uncovered in the streets, and ragged, vacant people huddled around fires. The clearing station was on the first floor of a badly damaged, crumbling building. Several "doctors" were in attendance, but they turned out to be students, a misunderstanding that led to an overestimation of the Russian medical response. I was introduced to a surgeon who said that a single surgeon did a 24 hour shift and then returned to Yerevan.

On returning to the Austrian camp I had my first meal for some time by the camp fire. A few hours earlier Red Cross workers had rescued a pregnant woman who had been trapped for five days. She had delivered her baby and had held it between her legs; the baby was dead and her legs lifeless. She was the last documented survivor but died later after having both 
legs amputated. Heavy lifting gear flown in by the Austrians had been hijacked at gunpoint by local Armenians; the rescue workers had been forced to rework a site by relatives, though they were released unharmed after 12 hours. Because of the curfew the Austrian army would not return me to the United States camp till dawn; the two members of the rescue team had arrived back after spending all night working on the site without finding a child. Other team members later joined other groups in various locations, but after 48 hours it became clear that the rescue attempt was over. We returned to Yerevan by aeroplane and spent several days helping in different hospitals.

Our impression was that the death toll in Leninakan was at least four times the official figure of 25000 . Most people had died instantly. Survivors were mostly uninjured people from the street or those who had small peripheral injuries from falling masonry; some people with severe injuries made it to a reasonable hospital, but many died subsequently. The sense of desolation and despair was tangible. All the usual "helping" agencies had been destroyed, and all four hospitals had been flattened. If the local response is to be effective it must first survive the disaster, a fact often forgotten when unwarranted criticisms are made.

\section{Lockerbie}

Two days after our arrival home Pan Am flight 103 exploded in mid-air and crashed into the Scottish town of Lockerbie. A telephone call from Royal Air Force Edinburgh said that two helicopters were to be diverted to Manchester to pick up the rescue team. We had 20 minutes to get to the airport. After a flight of 75 minutes we landed by a large crater that was burning fiercely. The police transported us to the command and control centre in the town, where a local general practitioner was site medical officer. A team from Edinburgh Royal Infirmary was already on site, and several local immediate care doctors were working with them. We split up and accompanied rescue teams over the hills. We found many bodies: those that had left the aircraft at altitude were naked but mostly intact.
We could only tag them because the investigators had instructed that nothing should be moved until photographed and videoed. We moved across the hills in the dark, feeling and looking for human remains. The ambulance crews were tense and fearful of finding someone in need of resuscitation and expressed relief at having medical help at hand. The possibility of finding injured townsfolk remained high, and the search continued without a break.

As day broke we were out again, this time to the site where a large section of fuselage had fallen on houses. A row of gardens was strewn with bodies, Christmas presents, clothes, and luggage, perhaps the most harrowing image that remains. At $2 \mathrm{pm}$ we stood down as more doctors had arrived to accompany the search. Human remains are confidently and quickly identified by doctors, and rescue workers appreciate this. We should not lose sight of the effect our presence alone can have at such incidents. As no aircraft was available we were advised to take the train to Manchester; the fare was provided by a social worker as we had no money. We arrived back at $7.30 \mathrm{pm}, 24$ hours after the disaster.

\section{Disaster coordination needed}

Planning for major incidents in the United Kingdom relies almost exclusively on the local response, in spite of the call for and use of outside help in recent incidents. The alerting, dispatch, and coordination of this help should be through a disaster coordination centre. This centre would ensure that additional help is drawn from a recognised pool of experienced teams. When required to respond abroad a small core team should be dispatched first, ideally by military aircraft, directly to the site of the disaster to assess the specific nature of any further aid. Doctors are a crucial part of the rescue attempt for triage, appropriate resuscitation, rapid and accurate identification of human remains, and the care of rescuers themselves. They must already have had experience of on site medical care and functioned as part of a multidisciplinary team.

(Accepted 23 fune 1989)

\title{
How To Do It
}

\section{Prepare a Festschrift}

\author{
Greg Wilkinson
}

The word Festschrift (German fest, festival; schrift, writings; Pl. -en, -s) is commonly used to designate the volume of essays, papers, and the like prepared by colleagues and friends as a tribute to a scholar or savant on some special occasion-usually on reaching a certain age, stage of career, retirement, or anniversary. "Festschriften," as Gerd Buchdal says, "are for men who have put their stamp on some branch of enquiry during a certain period of time." Although the first recorded use of the word in English was in 1901, there is still no satisfactory English equivalent. The preparation of a Festschrift is most commonly undertaken in the German speaking countries. Elsewhere it is much less common, more often a tribute to distinguished figures in the humanities and the basic sciences than in medicine.

Until now there has been no generally accepted method of preparing a Festschrift: varieties differ considerably in form and content. The typical format is most often that of a special issue or supplement of a learned journal, or of an obscure publication, rarely read (except by the recipient) and destined for a neglected library shelf. Many, if not most, examples of the genre, whether emanating from the arts or sciences, emerge as no more than an ephemeral medley of stale material, reminiscences and anecdotes, flavoured with flattering commentaries on the person concerned.

As a consequence, the task of preparing a Festschrift is often perceived as a dutiful chore, a secular act of devotion designed to give pleasure to the recipient but mainly heartache to the editors. Too much effort surrounds the preparation and too little thought is given to the purpose.

Accordingly, when my colleagues and I decided to embark on a Festschrift for Professor Michael

\section{London SE5 8AF \\ senior lecturer}

BrMed F 1989;299:612-4
BMJ VOLUME 299

2 SEPTEMBER 1989 